\title{
MANAGEMENT OF MYELOMENINGOCELE : EIGHT YEARS EXPERIENCE IN DHAKA MEDICAL COLLEGE AND HOSPITAL
}

\author{
K HASINA ${ }^{1}$, MA ALAMGIR ${ }^{2}$, SMS ENAYET ${ }^{3}$, A HANIF $^{4}$, MMM PERVEZ $^{5}$, S ALAM ${ }^{6}$
}

\begin{abstract}
Introduction: Myelomeningocele is a single most common congenital malformation that affects the entire central nervous system and because of extensive internal CNS involvement, its management remains controversial. Proper management of affected children can lead to a meaningful and productive life, and poorly managed cases of myelomeningocele can be a devastating obstacle not only for patient but also for the patient's family.

Materials and methods: This was a descriptive study, started in January, 2007 and completed in December 2014 in the Department of Pediatric Surgery and Department of Neurosurgery of Dhaka Medical College \& Hospital (DMCH).The medical records of 42 children with myelomeningocele operated at our center were reviewed retrospectively. The surgical \& medical management protocol used for different sites of myelomeningocele was studied.
\end{abstract}

Results: The age of most of the patients at the time of myelomeningocele repair was between 45 days to 60 days; however, children with ruptured myelomeningocele were consistently repaired early after controlling infection. In our study, 16 patients (38.1\%) of myelomeningocele with

1. Dr. Kaniz Hasina. Associate professor, Dept. of Pediatric Surgery, Dhaka Medical College \& Hospital, Dhaka

2. Dr. Md. Abdullah Alamgir, Assistant Professor, Clinical Neurosurgery, National Institute of Neuroscience, Dhaka

3. Dr. SM Sabbir Enayet, Resident, Dept of Pediatric Surgery, Dhaka Medical College \& Hospital

4. Dr. Abdul Hanif, Professor, Dept. of Pediatric Surgery, Dhaka Medical College \& Hospital, Dhaka

5. Dr. M.M. Masud Pervez, Assistant Professor, Dept of Pediatric Surgery, BIRDEM General Hospital. Dhaka

6. Dr. Saima Alam, Intern doctor, Dept of Pediatric Surgery, Dhaka Medical College \& Hospital

Correspondence to : Dr. Kaniz Hasina, Associate Professor, Department of Pediatric Surgery, Dhaka Medical College \& Hospital, Dhaka 1000, Bangladesh. E-mail: kanizhasina @gmail.com hydrocephalus were operated for medium pressure ventriculoperitoneal (VP) shunt first, and then repair after 7 days to 10 days. VP shunt was done 7 days after repair of myelomeningocele in 11 patients (26.19\%), who developed hydrocephalus postoperatively. All 8 patients with ruptured myelomeningocele $(19.05 \%)$ were treated for ventriculitis first, then by repair. Seven patients $(16.67 \%)$ with intact lesion were repaired between 4 weeks to 8 weeks of age.

Complications including CSF leak, wound infection, wound dehiscence, paraplegia, autonomic incontinence, shunt infection and malfunction after repair of myelomeningocele occurred in 27 patients $(64.29 \%)$. Six patients (14.29\%) died during treatment protocol. All the patients were followed up postoperatively for 6 months to 1 year.

Conclusion: Surgical intervention with or without VP shunt of patients with myelomeningocele produced good results.

Key words: Myelomeningocele; Repair; V-P shunt; Postoperative complications.

\section{Introduction:}

Myelomeningocele is the most common form of neural tube defect (NTD), a term used synonymously with spina bifida aperta, spinabifida cystica that affects the entire central nervous system and because of extensive internal CNS involvement, its management remains controversial ${ }^{1-6}$. On the other hand, the potential for prevention of the myelomeningocele like neural tube defects in the developing countries, is still far from being fulfilled and there is great need to increase awareness among the general public regarding etiological factors of this disastrous anomaly and its prevention by appropriate prenatal care. Other needs to address are availability of medical facilities and legal, moral, economical, social 
and humanitarian issues. Proper management of affected children can lead to a meaningful and productive life, and poorly managed cases of myelomeningocele can be a devastating obstacle not only for patient but also for the patient's family. The management plan must address some important issues before implementation such as which of the patients will benefit from treatment, the timing of repair, the diagnosis of ventriculitis and its optimal treatment, identification of hydrocephalus and the best time and the best technique for CSF shunting. Initially, the ventricles may be normal or only slightly enlarged. However, after the NTD is closed, the ventricles often enlarge. The incidence of hydrocephalus associated with myelomeningocele ranges from $80 \%$ to $95 \%$. The world literature is insufficient for accurate prediction of long-term prognosis for children with myelomeningocele and for formulary the comprehensive parameter regarding treatment indications. We are going to share our experience in the management of myelomeningocele with other health professionals.

\section{Materials and methods:}

The medical records of all children with myelomeningocele treated at $\mathrm{DMCH}$ during the year 2007-2014 were reviewed retrospectively. The records of the patients were analyzed for sex, location and size of lesion, CSF leakage, head size at birth and at the time of procedures, presence of hydrocephalus, type of surgery either repair or CSF shunting, use of prophylactic antibiotic, postoperative complications, and total hospital stay. After admission, a thorough physical examination was performed that includes measurement of head circumference, anal sphincter function (anocutaneous reflex or anal wink); upper and lower extremity motor and sensory function; the site, level, and size of the myelomeningocele defect; and whether or not the defect was leaking CSF. The defect size in our series was an average $25.9 \mathrm{~cm}^{2}$. In addition, the neonate was evaluated for signs and symptoms of hydrocephalus and other associated anomalies. The myelomeningocele defect was covered with sterile saline-soaked gauze to prevent desiccation of the exposed neural tissue. Broad-spectrum antibiotics were administered to reduce the risk of CNS infection. Head ultrasonography or computed tomography $(\mathrm{CT})$ was performed in all the cases to evaluate the extent of ventricular enlargement and determine the need for shunt placement. Prophylactic antibiotics were used with daily dressing of myelomeningocele depending upon the condition of skin over the lesion. CSF examinations were performed in only those cases where skin cover over the lesion was either infected or exhibited leakage. Myelomeningoceles were operated urgently in cases with evidence of CSF leakage after treating the ventriculitis depending upon CSF analysis. Repair was carried out using standard technique ${ }^{3}$ (separation of the neural placode from the intermediate zone of epithelium and reconstruction of the placode into a tube with preservation of all neural tissue; separation of the dura from the epidural space at the lateral margins of the defect and closure of the dura in a watertight but patulous fashion around the newly created NT, mobilization and midline approximation of the paraspinal muscles and fascia; and tension-free closure of the skin in the midline). Myelomeningoceles with hydrocaphalus $(n=16-38.1 \%)$ were treated with medium pressure VP shunt initially and then, repair after 7 days to 10 days. All other cases were repaired with standard procedures. Those who developed hydrocephalus postoperatively, treated with VP shunt insertion after 7 days of repair.

\section{Results:}

In our series of 42 cases there were 25 (59.52\%) boys and $17(40.48 \%)$ girls. The defect was located in the lumbosacral area $33(78.57 \%)$ cases, in thoracolumbar area $2(4.76 \%)$ cases, and the thoracic area 7 (16.67\%). The defect size was an average $25.9 \mathrm{~cm}^{2}$. The membrane was intact in 34 cases $(80.95 \%)$ and ruptured in 08 cases $(19.05 \%)$.

Table I

Frequency of Myelomeningocele according to region

\begin{tabular}{lc}
\hline Region & Percentage \\
\hline Thoracic & $07(16.67 \%)$ \\
Thoracolumbar & $02(4.76 \%)$ \\
Lumbosacral & $33(78.57 \%)$ \\
\hline
\end{tabular}

Table-II

Mode of presentation

\begin{tabular}{ll}
\hline Myelomeningocele & Percentage \\
\hline Intact & $34(80.95 \%)$ \\
Ruptured & $08(19.05 \%)$ \\
\hline
\end{tabular}


We treated $08(19.05 \%)$ cases of ruptured lesion with either free flow of CSF or minor leak having signs of ventriculitis with antibiotics first for controlling the infection, followed by repair as soon as possible. Hydrocephalus was diagnosed in 16 cases $(38.1 \%)$ either before admission to hospital or after hospitalization, and all were treated with the insertion of VP shunt first, and then repair after 7 days to 10 days. In 26 cases (61.9\%), hydrocephalus was absent initially but developed postoperatively in 11 cases $(26.19 \%)$ where the shunt was placed after 7 days of repair. All other myelomeningoceles were repaired with standard techniques at an average age of 6 weeks. The average duration of myelomeningocele repair including anesthesia was 1 hour 30 minutes. All patients received prophylactic antibiotics. Six patients $(14.29 \%)$ died in this series during treatment period.

Table-III

Associated hydrocephalus

\begin{tabular}{lc}
\hline Hydrocephalus & Percentage \\
\hline Present & $16(38.1 \%)$ \\
Absent & $26(61.9 \%)$ \\
\hline
\end{tabular}

Table-IV

Postoperative complications

\begin{tabular}{lc}
\hline Complications & Percentage \\
\hline CSF leak & $23(54.76 \%)$ \\
Wound infection and wound & $09(21.43 \%)$ \\
dehiscence & \\
Paraplegia & $11(26.19 \%)$ \\
Autonomic incontinence & $13(30.95 \%)$ \\
Shunt infection & $07(16.67 \%)$ \\
Shunt malfunction & $05(11.90 \%)$ \\
\hline
\end{tabular}

Postoperative complications including CSF leak, wound infection and wound dehiscence, paraplegia, autonomic incontinence, shunt infection and malfunction occurred in 27 cases $(64.29 \%)$. Uneventful postoperative period was observed in 09 patients $(21.43 \%)$ and 06 patients (14.29\%) died during postoperative period. The average hospital stay for all the cases was 15 days.

\section{Discussion:}

Developing countries are facing many problems; socioeconomic, cultural, educational and nutritional that result in congenital anomalies of CNS such as NTDs more frequently than developed countries like the USA or Europe. NTD involves entire central nervous system and leads to disability or death. The most common form of neural tube defect is myelomeningocele, a term used synonymously with spina bifida aperta, spinabifida cystica and open neural tube defect. The prevalence of myelomeningocele has declined in developed countries of the world owing to both prenatal folate supplementation and to pregnancy termination following prenatal diagnosis. In United States before 1980 prevalence of myelomeningocele was $1-2 / 1000$ live births, but more recently prevalence has declined to 0.44 per 1000 live births. ${ }^{11,12}$ Unfortunately, in developing countries prevalence is much higher, and acceptable prevalence data are not available, nor has the issue been addressed with the goal of eradication, or reduction of incidence. The cause of myelomeningocele is multifactorial and includes genetic predisposition, nutritional deficiencies, particularly folate and zinc, use of antiepileptic drugs like carbamazepine or valproic acid, diabetes mellitus (type-1), pre-pregnancy obesity and possibility other non medical factors such as agricultural pesticides, radiation, hyperthermia and use of tobacco or drugs. In our series all patients had undergone CT scan of brain and US of the myelomeningocele to determine ventricular size, size of the lesion and other anomalies like abnormal shaped mid brain. We had $02(4.76 \%)$ myelomeningoceles located at thoracolumbar region, $33(78.57 \%)$ at the lumbosacral region, and 7 cases $(16.67 \%)$ at thoracic region, and 16 cases $(38.1 \%)$ associated with hydrocephalus. Our aim was to assure an independent and productive life for patients with myelomeningocele and their families with reference to normal intelligence, sphincter control, and power in lower limbs and other spinal anomalies like scoliosis and kyphosis due to tethering of the cord. It is generally accepted that repair ideally should be performed 72 hours after birth to avoid ventriculitis. ${ }^{4,5}$ In our series 08 cases (19.05\%) were repaired early because of CSF leak. In rest of the cases, time of repair was between 45 days to 60 days, due to delayed referral of the cases as well as giving time to develop surrounding muscles and fascia to cover the gap. All cases were treated with antibiotics before repair. In all infected cases shunt surgery was delayed, until investigation and treatment for ventriculitis was successful. In our series, myelomeningoceles with hydrocaphalus $(n=16$ - 
$38.1 \%$ ) were treated with medium pressure VP shunt initially and then, repair after 7 days to 10 days. All other cases were repaired with standard procedures. Those who developed hydrocephalus postoperatively, treated with VP shunt insertion after 7 days of repair. The main purpose of myelomeningocele repair is to protect the functional tissue in the neural placode, to prevent loss of CSF and minimize the risk of meningitis by reconstructing the neural tube and its coverings with a stable soft tissue closure. To avoid complications, use of lumbar periosteal turn over flap and tissue expansion for delayed closure of large myelomeningocele has been advocated. ${ }^{3,12}$ Recently, rectal monitoring during repair of myelomeningocele has been performed to preserve neural tissues. ${ }^{7}$

In our series, postoperative CSF leak was found in 23 cases $(54.76 \%)$, wound infection and wound dehiscence in 09 cases $(21.43 \%)$, paraplegia in 11 cases $(26.19 \%)$, autonomic incontinence in 13 patients (30.95\%), shunt infection in $07(16.67 \%)$ and shunt malfunction in 05 cases $(11.90 \%)$. All the patients were followed up postoperatively for 6 months to 1 year. In our follow up we had not detect deterioration of neurological function in neurologically intact group.

\section{Conclusions:}

Children born with myelomeningocele usually have paralysis or weakness of the muscles below the level of their spine where the defect is. They also may not be able to control their bladder or bowels. Repair of a myelomeningocele is needed to prevent infection and further injury to the child's spinal cord and nerves. There is strong need of public health awareness program in all under developed countries with special reference to nutritional needs like folic acid deficiency. Early surgical repair of myelomeningocele with or without VP shunts shows very encouraging results.

\section{References:}

1. Blount JP, Tubbs RS, Okor M, Tyler-Kabara EC, Wellons JC 3rd, Grabb PA, Oakes WJ. Supra-placode spinal cord transaction in paraplegic patients with myelodysplasia and repetitive symptomatic tethered spinal cord. J Neurosurg 2005; 103:36-9.

2. Cohen-Gadol AA, Nahed BV, Voorhees JR, Maher $\mathrm{CO}$, Spencer DD. Historical vignette: Cushing's experience with the surgical treatment of spinal dysraphism. J Neurosurg 2005;102:441-4.

3. Fiala TG, Buchman SR, Muraszko KM. Use of lumbar periosteal turn over flap in myelomeningocele closure. Neurosurgery 1996;39(3):522-6.
4. Fitzpatrick MO, Taylor WA. Anterior sacral meningocele associated with a rectal fistula. J Neurosurg (1 Suppl) 1999; 91: 124-7.

5. Gilbert JN, Jones KI, Rroke LB ,Chernoff GF, James HE. Central nervous system anomalies associated with meningomyelocele, hydrocephalus, and the Arnold-Chiari malformation: Reappraisal of theories regarding the pathogenesis of posterior neural tube closure defects. Neurosurgery 1986;18:559-64.

6. Gupta DK, Mahapatra AK. Terminal myelocystoceles: a series of 17 cases. J Neurosurg 2005;103:344-52.

7. Ikeda K, Kubota T, Kashihara K, Yamamoto S. Anorectal pressure monitoring during surgery on sacral lipomeningocele. J Neurosurg 1986; 64:155-6.

8. Iskandar BJ, Fulmer BB, Hadley MN, Oakes WJ.Congenital tethered cord syndrome in adults. J Neurosurg 1998; 88:958-61.

9. James HE, Lubinsky G. Terminal myelocystocele. J Neurosurg 2005; 103: 443-5.

10. Lee KS, Gower DJ, McWhorter JM, Albertson $D A$. The role of MR imaging in the diagnosis and treatment of anterior sacral meningocele .Report of two cases.J Neurosurg 1988;69:628-31.

11. McNeely PD, Howes WJ. Infectiveness of dietary folic acid supplementation on the incidence of lipomyelomeningocele: pathogenic implications. J Neurosurg 2004;100:98-100.

12. Mowatt DJ, Thomson DN, Dunaway DJ. Tissue extension for the delayed closure of large myelomeningocele. J Neurosurg 2005;103:544-8.

13. Nejat F, Kazmi SS. Spontaneous resorption of a sacralmeningocele.Case illustration. J Neurosurg 2005;103: 94.

14. Steinbok P, Cochrane DD. The nature of congenital posterior cervical or cervico thoracic midline cutaneous mass lesions. Report of eight cases. J Neurosurg 1991;75: 206-12.

15. Tamaki N, Shirataki K, Kojima N, Shouse nY. Tethered cord syndrome of delayed onset following repair of myelomeningocele. J Neurosurg 1988; 9:393-8.

16. Vernet $\mathrm{O}$, Farmer JP, Houle AM ,Montes JL. Impact of urodynamic studies on the surgical management of spinal cord tethering. J Neurosurg 1996;85:555-9.

17. Warder DE, Oakes WJ. Tethered cord syndrome and the conus in a normal position. Neurosurgery 1993;33:374-8. 